The integration of

children with Down

syndrome in

mainstream primary

schools: Teacher

knowledge, needs, attitudes and expectations

\section{Heather Petty}

Monkwearmouth College,Sunderland, U.K.

\section{and Jane Sadler}

\author{
Department of Speech, \\ University of Newcastle upon Tyne,
}

\begin{abstract}
Nine mainstream primary teachers from one LEA in the North East of England (six with past and three with present experience of pupils with Down syndrome) took part in a study which aimed to identify those factors which may influence the outcome of full integration. Teacher knowledge, attitudes and expectations, levels of support and perceived needs were examined by means of semi-structured interviews and a questionnaire. A pilot information pack was developed on the basis of their perceived needs. Findings showed an increase in the number of children with Down syndrome integrated into mainstream primary schools, more pre-placement information regarding the child and higher levels of additional classroom staff than in the past. The main source of teacher knowledge was from background reading, the majority of teachers having received little or no input on SEN or Down syndrome during initial training or in-service apart from that offered by the Down's Syndrome Association in two cases. While parental involvement was seen as an additional source of information by a few teachers, it was not generally either very frequent or highly valued. Teacher attitudes to integration and their expectations regarding the social and academic abilities of their pupils with Down syndrome varied considerably. This variation appears to be related not only to personal factors such as the perceived ability to meet the children's needs and degree of specialist knowledge, but also to external factors such as the degree of classroom support, information/resources and professional guidance available. All teachers who took part in the study were unanimous in the need to improve integration.
\end{abstract}

\section{Acknowledgements}

Sincere thanks go to the teachers who participated in this study, and the parents and children who took part in the video clips for the pilot information pack.

\footnotetext{
(c) 1993, 1999. The Down Syndrome Educational Trust Down Syndrome Research and Practice

1996, 4 (1) 15-24
}

\section{Introduction}

Integration has been an issue of increasing momentum for all children with 'Special Educational Needs', including those with Down syndrome, since the introduction of the Warnock Report into government policy with the Education Act of 1981 and more recently with the Code of Practice and Education Act of 1993.

With a diagnosis of Down syndrome implying severe sub normality prior to the 1970's and therefore 'ineducability', it is not surprising that mainstream provision for these children has not always met with consensus amongst teachers. Attitudes and beliefs are notoriously slow to change, and children with Down syndrome may still be considered by some in terms of a set of stereotypes often related to outdated information and approaches, even though there is now evidence to indicate the wide range of intellectual ability to be found amongst such children, and published reports of their successful integration into mainstream classes (Lorenz, 1985, Bird and Buckley, 1994).

The effect of teacher attitudes and expectations on pupils is well documented in the literature. Studies such as those of Webster and McConnell (1987) and Hegarty (1993) suggest that children not only tend to conform to the expectations held by their teachers, but also that the extent to which these are communicated influence both the way children perceive themselves and the manner in which they are viewed by their peers (Carpenter, 1995). Kunsweiler (1982) found that real growth in teacher attitudes is a prerequisite of successful integration, even going so far as to claim that attitudes are more important than the degree of disability. This view is supported by Beveridge (1993) and Carpenter (1995) who maintain that the critical factor for successful integration is the school philosophy and the attitude of the staff .

However, the attitudes and behaviours demonstrated by teachers will in turn be affected by a range of factors. These include the teacher's past experiences, knowledge and understanding of special educational needs, and the degree of confidence in their professional ability to meet these needs, as well as the quality and availability of any support provided.

The role, therefore, of the teacher in ensuring effective integration for children with Down syndrome should not be underestimated. As Fulcher (1993) points out, in integration policy it would appear that "teachers matter at least as much as government level policies" as the latter do not have direct control over the school in relation to teaching styles and educational practices. In fact, when identifying certain aspects which characterise school environments that are conducive to the successful integration of children with special educational needs, Ainscow and Muncey (1988) concluded that the essential ingredients were: 1 ) effective leadership from a head teacher who is committed to meeting the needs of all pupils; 2) confidence among the staff that they can deal with individual children's needs; 3) a sense of optimism that all pupils can succeed; 4) arrangements for supporting individual members of staff; 5) a commitment to provide a broad and balanced range of curricula for all children and 6) systematic procedures for monitoring and reviewing progress.

However, with much of the initial impetus to make mainstream education available to children with Down syndrome 
arising from parents (Casey et al., 1988, Petley, 1994), the needs and attitudes of those mainstream teachers who are directly responsible for the educational needs of these children have remained either largely unidentified or taken second place to the needs of this pressure group and their children. Yet, it is against the attitudes and beliefs of such teachers that the recognition of the abilities and achievements of children with Down syndrome must be established for effective integration to be feasible.

\section{Purpose and aims of the present study}

The purpose of the present study was, therefore, to identify those factors which may influence the outcome of full integration of children with Down syndrome in mainstream primary classes, and on the basis of information gathered, attempt to respond in part to teachers' perceived needs by designing a pilot information pack for distribution to those teachers who currently have a pupil with Down syndrome in their mainstream class.

The specific aims were:

1) to examine, by means of semi-structured interviews and questionnaires, the specialist knowledge, attitudes and expectations of mainstream primary teachers with either past or present experience of pupils with Down syndrome within an integrated environment;

2) to establish the type and degree of provision of support and information available to these teachers, their perceived needs in relation to such, and how, in their opinion, these needs might best be met;

3) to develop a pilot information pack on the basis of information gathered from these teachers which would be evaluated at a later date.

\section{Method}

\section{Subjects}

All teachers from one LEA in the North East of England with past or present experience of teaching pupils with Down syndrome in mainstream primary classes were invited by letter to participate in the study. All but one of the ten teachers fulfilling these criteria agreed to take part. The nine subjects were then divided into two groups as follows:

Group 1 = six teachers with past experience of pupil/s with Down syndrome in primary mainstream classes;

Group 2 = three teachers with current experience of pupil/ $s$ with Down syndrome in primary mainstream class.

\section{Procedure}

\section{Part I}

Two questionnaires were developed and administered orally during a tape recorded, semi- structured interview of approximately thirty minutes held at the school of each subject. All participants were assured of anonymity. Responses were then clustered according to the main areas under investigation for each group of teachers and qualitative and quantitative analyses carried out.

\section{Part II}

Following the analysis of relevant data from the semistructured interview and the questionnaire, a pilot information pack was developed from a wide variety of sources and distributed to Group 2 teachers for evaluation at a later date (see Appendix I for list of contents). The sources of information for material contained in this pack included specialist literature, from telephone and personal contact with parent groups and a range of professionals involved with children with Down syndrome or with an interest in similar approaches. The following rationale was used in the compilation of this pack:

- to respond wherever possible to the needs expressed by Group 1 and Group 2 teachers as identified during the semi-structured interview and the questionnaire;

- to be a resource suitable for teachers with different degrees of knowledge of children with Down syndrome by supplementing basic information with additional references and sources for accessing further information and resources as required;

- to provide background information on the 'typical pattern' of social, cognitive and linguistic development while emphasising the individuality of children with Down syndrome;

- to provide information on tried and tested 'routes of learning' for children with Down syndrome;

- to develop understanding/knowledge of current issues and research regarding integration /inclusion of children with Down syndrome in mainstream primary classes;

- to provide information in a jargon free, easily accessible style, including check lists, and video clips.

\section{Results}

\section{Knowledge and experience of pupils with Down syndrome}

It can be seen from Table 1 that, apart from one teacher, the two subject groups had little experience of children with Down syndrome outside education, and only one teacher from each group had taught more than one such pupil.

Regarding the level and source of teacher knowledge of Down syndrome, it is evident from Table 2 that while just over half of the teachers in both groups remembered having received some input regarding Special Educational Needs in their initial teacher training, only one teacher reported this as having been specifically related to children with Down syndrome; input which this teacher had not found useful in catering for his/her present needs. Of the two teachers who reported having been given the opportunity to attend inservice training on SEN, one had also attended some related specifically to children with Down syndrome. However, the seven other teachers reported different degrees of background reading on the topic as their means of increasing their knowledge.

\section{Type, source and value of support received}

Teacher responses to questionnaire items investigating the degree of pre-placement information they received 
Table 1. Type of teacher experience with children with Down syndrome.

\begin{tabular}{|c|c|c|c|c|c|c|c|c|c|}
\hline \multirow{2}{*}{$\begin{array}{l}\text { Experience of children } \\
\text { with Down syndrome }\end{array}$} & \multicolumn{6}{|c|}{ Group 1} & \multicolumn{3}{|c|}{ Group 2} \\
\hline & 1 & 2 & 3 & 4 & 5 & 6 & 1 & 2 & 3 \\
\hline Number outside education: & 0 & 0 & 1 & 0 & 6 & 0 & 0 & 0 & 0 \\
\hline \multirow{3}{*}{$\begin{array}{l}\text { Number as own pupils: } \\
\text { - age of pupil/s (in years) } \\
\text { - mainstream class }\end{array}$} & 1 & 1 & 1 & 1 & 3 & 1 & 2 & 1 & 1 \\
\hline & 5 & $4-5$ & $6-7$ & 7 & $3-6$ & 6 & $4-5$ & 5 & 8 \\
\hline & $\mathrm{R}$ & $\mathrm{R}$ & Y2 & Y2 & $\mathrm{N}, \mathrm{R}$ & $\mathrm{R}$ & $\mathrm{N}, \mathrm{Y} 1$ & Y1 & Y3 \\
\hline
\end{tabular}

$\mathrm{N}$ : Mainstream nursery. I: Mainstream infants. J: Mainstream juniors. R: Reception year. Y: Year

Table 2. Level and source of teacher knowledge of Down syndrome.

\begin{tabular}{|c|c|c|c|c|c|c|c|c|c|}
\hline \multirow[t]{2}{*}{ Level and source of knowledge } & \multicolumn{6}{|c|}{ Group 1} & \multicolumn{3}{|c|}{ Group 2} \\
\hline & 1 & 2 & 3 & 4 & 5 & 6 & 1 & 2 & 3 \\
\hline \multirow{4}{*}{$\begin{array}{l}\text { Input in initial training: } \\
\text { - On SEN in general } \\
\text { - On Down syndrome } \\
\text { - Usefulness of input for present needs }\end{array}$} & & & & & & & & & \\
\hline & $\mathrm{X}$ & $\mathrm{F}$ & $S$ & $\mathrm{~N}$ & $S$ & $\mathrm{~N}$ & $\mathrm{X}$ & $\mathrm{S}$ & $\mathrm{S}$ \\
\hline & $\mathrm{N}$ & $\mathrm{N}$ & $\mathrm{N}$ & $\mathrm{N}$ & $\mathrm{S}$ & $\mathrm{N}$ & $\mathrm{N}$ & $\mathrm{N}$ & $\mathrm{N}$ \\
\hline & $\mathrm{n} / \mathrm{a}$ & no & no & $\mathrm{n} / \mathrm{a}$ & no & $\mathrm{n} / \mathrm{a}$ & $\mathrm{n} / \mathrm{a}$ & no & no \\
\hline \multicolumn{10}{|l|}{ In-service training: } \\
\hline \multirow{3}{*}{$\begin{array}{l}\text { - S.E.N. } \\
\text { - Down syndrome } \\
\text { - usefulness of input for present needs }\end{array}$} & no & no & no & no & yes & no & yes & no & no \\
\hline & no & no & no & no & yes & no & no & no & no \\
\hline & $\mathrm{n} / \mathrm{a}$ & $\mathrm{n} / \mathrm{a}$ & $\mathrm{n} / \mathrm{a}$ & $\mathrm{n} / \mathrm{a}$ & yes & $\mathrm{n} / \mathrm{a}$ & yes & $\mathrm{n} / \mathrm{a}$ & $\mathrm{n} / \mathrm{a}$ \\
\hline Background reading & $\mathrm{S}$ & $\mathrm{S}$ & $\mathrm{S}$ & $\mathrm{N}$ & $\mathrm{C}$ & $\mathrm{N}$ & $\mathrm{S}$ & $\mathrm{F}$ & $\mathrm{F}$ \\
\hline
\end{tabular}

X: Can't remember. N: None. S: Some. F: Fair amount. C: Considerable amount. SEN: Special educational needs.

Table 3. Source and value of pre-placement information.

\begin{tabular}{|c|c|c|c|c|c|c|c|c|c|}
\hline \multirow[t]{2}{*}{ Pre-placement information } & \multicolumn{6}{|c|}{ Group 1} & \multicolumn{3}{|c|}{ Group 2} \\
\hline & 1 & 2 & 3 & 4 & 5 & 6 & 1 & 2 & 3 \\
\hline Pre placement information & Yes & No & Yes & Yes & No & No & Yes & Yes & Yes \\
\hline Source of information. & $\mathrm{PP}$ & $\mathrm{n} / \mathrm{a}$ & $\mathrm{PT}$ & PT & $\mathrm{n} / \mathrm{a}$ & $\mathrm{n} / \mathrm{a}$ & PT & PT & $\mathrm{PT}$ \\
\hline Value of information & $\mathrm{R}$ & $\mathrm{n} / \mathrm{a}$ & $\mathrm{P}$ & $\mathrm{P}$ & $\mathrm{n} / \mathrm{a}$ & $\mathrm{P}$ & $\mathrm{R}$ & $\mathrm{P}$ & $\mathrm{RP}$ \\
\hline
\end{tabular}

PP: Previous psychologist. PT: Previous teacher. E: Excellent. R: Reasonably good. G: Good. RP: Rather poor. P: Poor.

Table 4. Frequency and perceived value of parental contact.

\begin{tabular}{|c|c|c|c|c|c|c|c|c|c|}
\hline \multirow{2}{*}{$\begin{array}{l}\text { Teacher contact with parents of } \\
\text { pupils with Down syndrome }\end{array}$} & \multicolumn{6}{|c|}{ Group 1} & \multicolumn{3}{|c|}{ Group 2} \\
\hline & 1 & 2 & 3 & 4 & 5 & 6 & 1 & 2 & 3 \\
\hline Frequency of contact & $\mathrm{D}$ & $\mathrm{T}$ & $\mathrm{W}$ & $\mathrm{R}$ & $\mathrm{D}$ & $\mathrm{D}$ & $\mathrm{R}$ & $\mathrm{W}$ & $\mathrm{D}$ \\
\hline Perceived value of contact & $\mathrm{H}$ & VH & $\mathrm{H}$ & LU & VH & LU & VU & VU & $\mathrm{H}$ \\
\hline
\end{tabular}

D: Daily. T: Termly. W: Weekly. R: Rarely. VH: Very helpful. LU: Little use. VU: Virtually useless.

regarding their pupil/s with Down syndrome and the perceived effectiveness of such are displayed in Table 3. Two thirds of all the teachers had received some preplacement information, which in all cases but one, where this information was given by the previous educational psychologist, had been provided by the previous class teacher. However, while these six teachers all had felt free to raise any concerns, it is evident that the overall rating regarding the utility of this pre-placement information/ preparation was not high, with six teachers rating the quality as being "poor" or "rather poor".
An additional source of information for teachers regarding their pupils with Down syndrome might have been the parents themselves. However, while Table 4 shows that support and partnership from parents was valued to some extent by five of the nine teachers, the degree of contact varied considerably from daily to termly. Furthermore, of the six teachers who did have regular contact with parents (either daily or weekly), three considered this contact to be either of 'little use' or 'virtually useless'. 
Table 5. Source, type and perceived effectiveness of teacher in-placement support.

\begin{tabular}{|c|c|c|c|c|c|c|c|c|c|c|}
\hline \multirow[t]{2}{*}{ Teacher responses } & \multicolumn{6}{|c|}{ Group 1} & \multicolumn{3}{|c|}{ Group 2} & \multirow[t]{2}{*}{ Total } \\
\hline & 1 & 2 & 3 & 4 & 5 & 6 & 1 & 2 & 3 & \\
\hline $\begin{array}{l}\text { Source of information: } \\
\text { - portage worker/teacher } \\
\text { - speech \& language therapist } \\
\text { - educational records } \\
\text { - educational psychologist } \\
\text { - parents } \\
\text { - support service } \\
\text { - library/literature } \\
\text { - info. pack Down's syndrome } \\
\text { - can't remember }\end{array}$ & $x$ & $\begin{array}{l}x \\
x\end{array}$ & $\begin{array}{l}x \\
x\end{array}$ & $\begin{array}{l}x \\
x\end{array}$ & $\begin{array}{l}x \\
x\end{array}$ & $\begin{array}{l}x \\
x \\
x\end{array}$ & $\begin{array}{l}x \\
x\end{array}$ & $x$ & $x$ & $\begin{array}{l}2 \\
1 \\
5 \\
3 \\
1 \\
2 \\
2 \\
1 \\
1\end{array}$ \\
\hline $\begin{array}{l}\text { Areas covered: } \\
\text { - motor/physical } \\
\text { - speech \& language } \\
\text { - behaviour/social } \\
\text { - general education } \\
\text { - general information } \\
\text { - can't remember }\end{array}$ & $x$ & $\begin{array}{l}x \\
x \\
x\end{array}$ & $\begin{array}{l}x \\
x \\
x \\
x\end{array}$ & $\begin{array}{l}x \\
x \\
x \\
x\end{array}$ & $x$ & $x$ & $x$ & $x$ & $\begin{array}{l}x \\
x\end{array}$ & $\begin{array}{l}4 \\
4 \\
4 \\
2 \\
3 \\
1\end{array}$ \\
\hline $\begin{array}{l}\text { Effectiveness of information } \\
\text { - very effective } \\
\text { - quite effective } \\
\text { - not very effective } \\
\text { - not at all effective } \\
\text { - no response }\end{array}$ & $x$ & $x$ & $x$ & $x$ & $x$ & $x$ & $x$ & $x$ & $x$ & $\begin{array}{l}0 \\
1 \\
3 \\
4 \\
1\end{array}$ \\
\hline Accessibility info/material & $\mathrm{Y}$ & $\mathrm{N}$ & Y & $\mathrm{Y}$ & $\mathrm{N}$ & $Y$ & $\mathrm{Y}$ & $Y$ & $\mathrm{Y}$ & \\
\hline
\end{tabular}

Y: Yes; N: No.

Table 6. Degree and value of classroom support staff.

\begin{tabular}{|c|c|c|c|c|c|c|c|c|c|}
\hline \multirow[t]{2}{*}{ Support staff } & \multicolumn{6}{|c|}{ Group 1} & \multicolumn{3}{|c|}{ Group 2} \\
\hline & 1 & 2 & 3 & 4 & 5 & 6 & 1 & 2 & 3 \\
\hline Additional staff & yes & no & yes & yes & yes & no & yes & yes & yes \\
\hline Status of staff & NN & $\mathrm{n} / \mathrm{a}$ & NTA & NTA & NTA & $\mathrm{n} / \mathrm{a}$ & ST, SN & NTA & NTA \\
\hline Weekly input & 0.5 & $\mathrm{n} / \mathrm{a}$ & $0.5-0.9$ & $0.5-0.7$ & FT & $\mathrm{n} / \mathrm{a}$ & $\mathrm{FT}$ & FT & 0.8 \\
\hline Benefit for teacher & very & $\mathrm{n} / \mathrm{a}$ & very & very & very & $\mathrm{n} / \mathrm{a}$ & very & very & $\begin{array}{l}\text { not } \\
\text { very }\end{array}$ \\
\hline
\end{tabular}

NN: Nursery nurse. SN: Student nursery nurse. NTA: Non-teaching auxiliary. ST: Support teacher. FT: Full time.

Responses to questionnaire items which examined the source, type and perceived value of any specialist support, advice or information made available to these teachers during the child's placement are displayed in Table 5. While in the past (Group 1 subjects), the main source of specialist support/information during the child's placement had been through school records or the educational psychologist, this was not the case with the three teachers (Group 2) who had children with Down syndrome in their class at present. Their main source of information/advice was school records and books. The areas of information covered varied considerably between the two groups, and in only 2 cases was reported as having been 'quite effective' in meeting their needs. The other seven teachers rated any support/materials/advice they had received while the child was in their class as either 'not very' or 'not at all effective'.
The reasons given for the ineffectiveness of the information included "too out of date", "impersonal, vague", "educational psychologist difficult to contact", and "lack of knowledge re: procedures and channels to go through".

Information regarding support personnel available within the classroom is identified in Table 6 along with the teachers' views concerning the value of such. All but two teachers in Group 1 had some classroom support provided by various levels of qualified status including non- teaching auxiliaries, nursery nurses, and in one case a full time support teacher. Of the three teachers in Group 2, two reported that this support provision was very beneficial, giving a variety of reasons such as "essential due to possible dangers". "teacher would panic if NTA (Non-teaching auxiliary) not there", "would not know what to do" "one to one attention essential at all times". Where it was not felt to be beneficial, the teacher 
Table 7. Teacher suggestions on type and medium of information required.

\begin{tabular}{|l|c|c|c|}
\hline Teacher suggestions & Group 1 & Group 2 & Total \\
\hline Type of information: & & & $\mathbf{4 1}$ \\
\hline - info/advice from previous placement & 3 & 3 & 6 \\
\hline - practical teaching advice/guidelines & 6 & 2 & 8 \\
\hline - troubleshooting guide & 3 & & 3 \\
\hline - summaries of relevant research findings & 2 & 2 & 4 \\
\hline - short reviews relevant literature & 4 & 2 & 6 \\
\hline - names \& addresses of agencies & 5 & 3 & 8 \\
\hline - list appropriate references/reading list & 4 & 2 & 6 \\
\hline Medium for information delivery: & & & $\mathbf{2 9}$ \\
\hline - visits to other placements & 2 & 1 & 3 \\
\hline - written information/advice left with teacher & 5 & 2 & 7 \\
\hline - video clips of practice & 4 & 1 & 5 \\
\hline - report/discussions with previous teachers & 4 & 3 & 7 \\
\hline - personal contact with trained professionals & 6 & 1 & 7 \\
\hline
\end{tabular}

Table 8. Teacher evaluation of the suitability of mainstream placement for their pupils with Down syndrome.

\begin{tabular}{|l|c|c|c|}
\hline Teacher responses & Group 1 & Group 2 & Total \\
\hline Suitability - Educationally: & & & $\mathbf{9}$ \\
- very suitable & 0 & 2 & 2 \\
- fairly suitable & 5 & 0 & 5 \\
- not very suitable & 0 & 1 & 1 \\
- not at all suitable & 0 & 0 & 0 \\
- no comment & 1 & 0 & 1 \\
\hline Suitability - Socially: & & & $\mathbf{9}$ \\
- very suitable & 4 & 2 & 6 \\
- fairly suitable & 0 & 1 & 1 \\
- not very suitable & 2 & 0 & 2 \\
- not at all suitable & 0 & 0 & 0 \\
\hline
\end{tabular}

reported that this was due to the lack of professional skills on the part of the non-teaching auxiliary.

A total of forty-one suggestions were received from the two groups of teachers regarding the type of information they thought they would find most useful in meeting their needs as mainstream teachers of pupils with Down syndrome, and twenty-nine on how best this information could be provided. It is evident from Table 7 that all Group 1 teachers (those who had had a pupil with Down syndrome in their class in the past) reported the need for practical teaching advice. Group 2 teachers, on the other hand particularly felt the need for preplacement information and contact addresses. Responses regarding the preferred medium for information differed slightly between the two groups; personal contact with professionals and written information left with teachers being the most frequent responses for Group 1 teachers, while Group 2 were unanimous regarding the need for reports and discussions with previous teachers.

\section{Teacher attitudes to the integration of pupils with Down syndrome}

The great majority of teachers in both groups stated that in their opinion mainstream placement was, or had been, either "very suitable", or "fairly suitable" from both a social and an educational point of view for their particular pupils with Down syndrome (see Table 8).
Among the reasons cited in favour of mainstream placement were "good models of language for the child" and the "ability of the pupil to make progress across all curriculum areas including the 3Rs, particularly in the early years". However, one teacher qualified this statement by adding that the gap in ability widened as the child grew older. The latter was also given by one teacher as a reason for a mainstream placement not being very suitable, as was "demands placed on child within class are too great" and the "child needs more teacher time than available". Regarding the social suitability, the reasons reported included the ability of the child to socialise well, to be accepted and be well liked by teachers and peers. Less positive reasons given tended to centre on aspects of peer interaction, with the child "treated as a toy" or "treated as younger sibling".

Additional information regarding teacher perceptions/attitudes to integration was investigated through questionnaire items where the two groups of teachers were asked to state what they considered to be the greatest strengths and weaknesses both educationally and socially of their pupils with Down syndrome. These are tabulated in Tables 9 and 10.

As might be expected, considering the individual differences likely to be found amongst these pupils, there was little 
consensus on the part of either group of teachers regarding their pupils' educational strengths or weaknesses (see Table 9), although two stated there were no educational strengths and three of the nine teachers commented on problems of concentration and the inappropriate level of class work. However, as can be seen in Table 10, a much greater accord was found regarding social strengths, with two thirds of all the teachers commenting on the affectionate, happy nature of their pupils and two teachers stating their pupils had no social weaknesses at all.

Attitudes to integration were investigated in the final questionnaire item where teachers were asked to state their views regarding the integration of pupils with Down syndrome in primary mainstream classes in general (see Table 11). Here only one teacher came out completely in favour of such integration. While three felt special school provision was more suitable, three teachers stated either specia school or mainstream, suggesting an openness towards mainstream placements. However, apart from one teacher in Group 2, all the others were unanimous in stating that behaviour problems could not be specifically associated with any particular type of placement, and all but one teacher claimed that the children would have more friends in the local community if they attended a mainstream school.

\section{Teacher proposals for facilitating integration}

There was a $100 \%$ consensus from both groups of teachers regarding the need to improve the present standard of integration of children with Down syndrome in mainstream primary classes. In Table 12 are displayed their suggestions as to how this might best be achieved.

While teachers provided a variety of different suggestions, it is evident here that the majority in both groups felt that, above all, integration could be improved by regular specialist input from outside agencies.

Table 9. Teacher estimate of educational strengths and weaknesses of their pupils with Down syndrome.

\begin{tabular}{|l|c|c|c|}
\hline Teacher estimates & Group 1 & Group 2 & Total \\
\hline Pupil's educational strengths : & 1 & & $\mathbf{9}$ \\
- reading & 1 & & 1 \\
- willingness to attempt everything & 1 & & 1 \\
- child directed concentration & 1 & 1 & 1 \\
- positive effect on other children & 1 & 1 & 2 \\
- don't know & 1 & 1 & 2 \\
- none & & & $\mathbf{1 1}$ \\
\hline Pupil's educational weaknesses: & 1 & & 1 \\
- need for simple one step instructions & 2 & 1 & 3 \\
- lack of concentration/ poor short term memory & 1 & & 1 \\
- slow academic progress & 2 & 1 & 3 \\
- class work/ level not appropriate for child & 1 & & 1 \\
- difficulty in following classroom routines & & 1 & 1 \\
- child not placed for educational reasons & & 1 & 1 \\
\hline
\end{tabular}

Table 10. Teacher estimate of the social strengths and weaknesses of their pupils with Down syndrome.

\begin{tabular}{|l|c|c|c|}
\hline Teacher estimates of their pupils & Group 1 & Group 2 & Total \\
\hline Pupils' social strengths: & 5 & 1 & $\mathbf{1 2}$ \\
- happy , friendly, affectionate, & 1 & & 1 \\
- extremely adaptable & & 1 & 1 \\
- independence, can be sent on messages alone & & 1 & 1 \\
- no tantrums or mood swings & & 1 & 1 \\
- good self image & 1 & & 1 \\
- enjoys music/singing & 1 & & 1 \\
- mixes well in groups & & & 9 \\
\hline Pupils' social weaknesses: & 1 & 1 & 2 \\
- none & 2 & & 2 \\
- dislikes conforming/sharing with peers & & 2 & 2 \\
- expressive language, initiating verbal interaction & 1 & & 1 \\
- being accepted by other children & 1 & & 1 \\
- dependent on routines & 1 & & 1 \\
- too boisterous & & & \\
\hline
\end{tabular}


Table 11. Teacher views on educational placement for pupils with Down syndrome.

\begin{tabular}{|l|llll|ll|lll|}
\hline \multirow{2}{*}{ Teacher views } & \multicolumn{3}{|c|}{ Mainstream } & \multicolumn{3}{c|}{ Special school } & \multicolumn{3}{c|}{ Either } \\
\cline { 2 - 11 } & G1 & $\mathbf{G 2}$ & $\mathbf{T}$ & $\mathbf{G 1}$ & $\mathbf{G 2}$ & $\mathbf{T}$ & $\mathbf{G 1}$ & $\mathbf{2}$ & T \\
\hline They are better off in: & 1 & 3 & 4 & 3 & - & 3 & 2 & - & 2 \\
\hline Acquire literacy skills better in: & 1 & 1 & 2 & 2 & 1 & 3 & 3 & - & 3 \\
\hline Learn to communicate better in: & 2 & 2 & 4 & 1 & - & 1 & 3 & - & 3 \\
\hline Show more behavioural problems in: & - & - & 0 & - & 1 & 1 & 6 & 1 & 7 \\
\hline Make more peer group relationships in: & 2 & 1 & 3 & 1 & - & 1 & 3 & 1 & 4 \\
\hline Have more friends in the local community: & 5 & 2 & 7 & - & - & 0 & 1 & - & 1 \\
\hline
\end{tabular}

G1: Group 1. G2: Group 2. T: Total

Table 12. Teacher proposals for improving integration of pupils with Down syndrome.

\begin{tabular}{|l|c|c|c|}
\hline Teacher proposals for improving integration & Group 1 & Group 2 & Total \\
\hline Additional classroom personnel & 1 & 1 & 2 \\
\hline More realistic expectations on the part of the teacher & 1 & 0 & 1 \\
\hline More initial preparation & 2 & 0 & 2 \\
\hline Need to evaluate effectiveness of programme & 1 & 0 & 1 \\
\hline Working with parents as partners & 1 & 2 & 3 \\
\hline Regular specialist input from outside agencies & 5 & 3 & 8 \\
\hline More written information/resources/inservice training & 2 & 2 & 4 \\
\hline
\end{tabular}

\section{Discussion}

When considering the findings reported in the previous section, it is important to bear in mind questions of validity and reliability related to the method of data collection. The delivery of a questionnaire during a semi-structured interview has the advantage over a postal questionnaire in that it permits rapport to be established, the observation of respondents, and clarification of responses as required (Sax, 1979). As Bell (1987) states, interviews "can yield rich material and often put flesh on the bone of questionnaire responses". However, interviews are also highly subjective techniques and as such open to bias on the part of both the interviewer (who may be influenced by what he or she hopes to prove), and the interviewee (Bell 1987), where respondent bias may be the result of an attempt to please the researcher or protect their own interests (Van Dalen, 1962). Although anonymity was assured all teachers, this must be a consideration in the present study, in particular in relation to responses on the emotive issue of integration.

It is apparent however, that, despite an increase in recent years in the number of pupils integrated into mainstream classes, teacher experience of pupils with Down syndrome within this particular LEA was very limited. Neither was this lack of experience counterbalanced by an increase in specialist teacher knowledge. Even in the case of those teachers more recently qualified, there was a noticeable lack of input in their initial training regarding special educational needs in general, and Down syndrome in particular. This suggests that Mittler's (1992) concerns, regarding the difficulty of implementation of the training standards on SEN set out by the 1984 Advisory Committee on the Supply and Education of Teachers (ACET), are well founded.

While in-service training might have filled this gap, according to the teachers it had not been readily available apart from two cases, one of which had been organised by the children's parents and provided on a voluntary basis by the local branch of the Down's Syndrome Association. That this input was reported by the teacher as being helpful in meeting his/her needs supports Beveridge's claim (1993) that where collaboration takes place between parents and teachers it will be to the benefit of the children concerned. However, contact with parents of children with Down syndrome did not always appear to be either frequent or very highly valued, although the majority of responses demonstrated respect and some appreciation of parental involvement. As Hegarty (1993) reminds us, schools have traditionally kept parents at arm's length except to discuss concerns regarding the child's moral or physical welfare, but changes in attitude on the part of some teachers and some parents will take time and patience to develop. In fact, Mortimore et al. (1988) and Petley (1994) found effective education to have been the result of factors such as constructive two-way communication between home and school. While it was not within the scope of the present study to investigate the various factors which might influence such collaboration, this aspect would merit more attention in that in several cases this potential source of highly pertinent information for teachers was lost.

The main source of teacher knowledge on Down syndrome, therefore, came from written material. That the degree of background reading engaged in by the teachers varied considerably may well be related in part to teacher motivation. In fact, the three teachers who reported having done no reading on the subject had not attended any in-service training on special educational needs either. However, apart from possible difficulties in accessing information, another interpretation is that these teachers were not in a position to appreciate the complexities surrounding the topic, not having received the opportunity to develop their awareness of Down syndrome and thus feel the need to acquire more specialist knowledge. This too would merit further investigation. 
It would appear, therefore, that it is left largely to the teachers themselves to find time to increase their knowledge of Down syndrome. However, considering that mainstream teachers must meet the needs of all the pupils in their classes, for some teachers this may not be a very high priority, or, where it is, the increased pressure on teacher time may become a source of resentment. This possibility was reflected in the comment of a recently qualified teacher who felt "particularly saddened" by the fact that there was "no compensation for time lost" when grappling with new ideas regarding the management and teaching approaches required to cater effectively with a child with Down syndrome.

Furthermore, the written information that was available to the teachers received low ratings regarding its perceived effectiveness. Not withstanding, the majority of teachers reported referring frequently to any information that was accessible; a finding which suggests that were materials made available to them which they perceived as appropriate and effective in meeting their needs, they would make good use of them despite the numerous pressures on their time.

Although, on the whole, there was a broad topic base, this seems to have been at the expense of sufficient detail, and the brevity of the information was of common concern. The effectiveness of information available appeared to be closely related to availability and the perceived appropriateness of such, with the layout and jargon free terminology also appearing to have been an important consideration. One specific area where teachers felt in need of help was information on task analysis including the methods and techniques involved in analysing the breakdown of tasks into smaller component parts. Those teachers who had previously received training in this area felt it to have been most beneficial and would have appreciated further input. Generally, there appeared to be a need for a specific skills base of knowledge and experience, including guidelines and information dealing with the teaching of reading, writing and numeracy. This information the teachers considered was essential if the children concerned were to be able to work towards and complete the National Curriculum attainment targets.

If, therefore, as this study suggests, the majority of mainstream teachers may have limited knowledge of the special needs of children with Down syndrome, it would appear to be essential that they are given all the necessary support when such a child is placed within their class. While little appears to have been done in the past within this particular LEA to ensure that all the teachers received pre-placement information regarding the specific pupils, this was no longer true with the three Group 2 teachers, suggesting that more effective mechanisms to ensure passage of information had since been put in place. This supports Petley's claim that headteachers and class teachers should make pre-placement visits to both the child and the parents in order to alliviate any anxieties that the teachers might have.

However, even where pre-placement information was forthcoming, it did not always meet teacher needs and this was also the case with regard to some information received during the placement itself. While this should not necessarily be interpreted as a reflection on the standard of the information received, it does at least suggest the need for more finetuning on the part of those who provide such input. It is possible that non-teacher professionals are making illfounded suppositions regarding the level of background knowledge possessed by teachers, or are unaware of the full implications for mainstream teachers of having to cater for the needs of children with this particular handicap. As Hergarty (1993) points out, for the successful passing on of information and skills, collaborative attitudes are not sufficient on their own as the same professional may not be able to communicate that same skill to another professional. Furthermore, as long as the main source of information continues to be previous teachers, the standard of information passed on is unlikely to rise notably unless they are given opportunities to acquire more specialist knowledge.

In fact, all teachers admitted to uncertainty regarding the potential range of abilities and the appropriate level of work to set their pupils with Down syndrome. This may well have affected their expectations and in some cases resulted in illfounded perceptions of a child's ability. It is interesting to note that the respondents who found difficulty in identifying any academic strengths in their pupils with Down syndrome were those who admitted to having little knowledge. However, some respondents did show awareness of their pupil's ability levels in academic subjects such as reading and mathematics, reflecting a level of knowledge about the child that went beyond recognition of behavioural and personality traits which all teachers were quick to identify.

It was very apparent that teachers felt the need of specialist support. In fact, the need for regular input from the Advisory or Learning Support Service was identified by all teachers who also stressed that this support should be from experienced personnel and be available from the onset of the placement, supporting the views of Petley (1994) who maintains the effectiveness of such support on a regular basis in relieving teacher anxiety. It is also interesting to note that this ongoing support was seen by some as a process which should serve to encourage and develop self-help strategies rather than solve problems for the teacher. This reinforces the viewpoint of Sugden (1989) and Beveridge (1993) who reported that when sufficient and appropriate outside support and training is provided, teacher confidence increases with the increase in knowledge, and teachers are then more prepared to form their own opinions and find solutions to their own problems.

While in the past the provision of additional classroom staff appears to have been erratic this fortunately was no longer true for the group of teachers who at the time of the study had pupils with Down syndrome in their class. The majority of support was provided by non-teaching auxiliaries who were allocated for the time that the children were in school. Most teachers appeared satisfied with this arrangement, although one teacher raised the issue of the lack of formal training of NTAs. In particular, the teacher of a child in a Year III group felt that the support offered the child should at this stage be of a qualified nature in order to meet the child's increasing educational needs.

Although teacher attitudes towards integration showed variation throughout the groups, there appears to have been a positive shift over the past few years; a finding also reported in other parts of the country (Bird and Buckley, 1994, Lorenz,1985., Casey et al., 1988 and Petley, 1994). According to Beveridge (1993), such a shift may be the result of an increase in awareness and acceptance of the role of main- 
stream schools in making special educational provision, and Sugden et al., (1989) found that where in-service opportunities were available to school staff, the vast majority were in favour of integrated provision of children with moderate learning difficulties. Certainly the present study suggests that positive teacher attitudes towards integration of children with Down syndrome are likely to be related to feelings of self confidence in their ability to meet the needs of such children and also to be influenced by the degree of support available, including classroom support, information/resources materials and professional guidance.

\section{Conclusion}

While acknowledging the risk of attempting to generalise findings from a small scale study to the population in general, it does not seem too improbable that a similar situation may be found elsewhere in the UK. Certainly, in this study of teachers with past or present experience of teaching children with Down syndrome in mainstream classes, the teachers were unanimous in the need to improve integration. Not only had the great majority of teachers little experience of such children, but perhaps more importantly had received little or no specialist training either during their initial training or their teaching career. The fact that, even where input had been provided in initial training, it was not felt to meet their present needs, must have serious implications for providers.

This perceived lack of specialist knowledge on their part resulted generally in low levels of confidence in their ability as mainstream teachers to fully cater for the needs of pupils with Down syndrome, and in some cases appeared not only to have affected their attitude towards integration, but also their expectations of the social and academic abilities of their pupils with Down syndrome. Obviously, for teacher expectations to be realistic they must be founded upon accurate information, but in order for teachers to assess the levels that need to be targeted with individual children with Down syndrome, it would appear that they need access to more hard information than was generally available.

However, it was encouraging to see that, in this particular LEA, children with Down syndrome were being integrated increasingly into mainstream classes, and that overall the attitude of these teachers towards the integration of children with Down syndrome was fairly positive, despite this acknowledged lack of specialist knowledge and suitable resources. Furthermore, a comparison of staffing levels of the two groups of teachers suggests a recent acknowledgement on the part of the LEA of the need for additional staff provision for these children; a finding which might explain, to some extent, the difference in attitudes between Group 1 and Group 2 regarding the suitability of mainstream placement for children with Down syndrome.

Certainly, attitudes appeared to be closely related to the degree of specialist support received. That this, teachers felt, should be consistent and available from the outset obviously requires the continued commitment of the local education committee, which, in an era of cutbacks affecting both finance and staff levels, may become harder to maintain.

There would appear to be the need for some long term planning, if, as the Fish Report (ILEA 1985) states, integration is to be seen as an ongoing process, not just a transient experience, in order that teachers fully take on board the educational responsibilities that go with the placement of any child within the class group. There is a body of evidence (Sugden et al., 1989; Bird and Buckley 1994; Petley 1994), which suggests that given an increased knowledge and understanding of a particular special need as well as special educational needs generally (for example via in-service training and/or professional support), a change in teacher perspective ensues. This was found, albeit in small measure, in the present study, with some teachers acknowledging a change in attitude by the end of the placement.

While the starting point for any change in teacher knowledge, attitudes and expectations should begin during the period of initial training, as recommended by the ACSET report (1984), most currently employed teachers will not be affected by any recent innovations in initial training. Yet, it is these teachers who are likely to hold positions of responsibility within schools and make decisions regarding curriculum and academic organisation for children with special needs. Therefore, as Hegarty (1993) stresses, there is the need for in-service training to be made available, as this is the most likely training to determine the extent to which effective reform will take place at a practical level. However, in providing this in-service, training establishments, LEAs and schools might do well to listen to the perceived needs of teachers, as there were clearly identified specific needs reported by the teachers in this study concerning the type, frequency, content and provision of support, information and advice required.

Although, as mentioned earlier, it was not within the scope of the present study to evaluate the effectiveness of the pilot information pack which was developed on the basis of information provided in the semi structured interview and the questionnaire, it is the intention in the future to develop this further so that it may provide a permanent school-based resource which may in part meet the needs as identified by teachers in this study.

Meantime, it is hoped that an additional outcome of this study has been that the teachers have become actively involved in reflecting on the process of integration. The teachers not only gave consideration to their own specific abilities and needs, but also reflected on those of their pupils; a process which should have been of benefit to all.

\section{Appendix}

\section{Contents of Information Pack}

1) General information re: Down syndrome and reference to the learning environment

2) Personality characteristics of children with Down syndrome.

3) Discipline: guidelines, strategies and interventions.

4) Gross motor skills: possible common characteristics, awareness and confidence.

5) Fine motor skills: development, motivation and support. 
6) Numeracy skills: stages, principles and mathematical language.

7) Reading and writing: rates to reading, progression and development of writing and spelling.

8) Speech and language development: patterns of development; use of sign; motivation and intervention.

9) Hearing and listening skills: ability and development.

10) Short and long term memory: capacity, training and advantages of visual processing.

11) Video relating to local good practice.

\section{References}

Advisory Committee on the Supply and Education of Teachers (ACSET) (1984). Teacher Training and Special Educational Needs. London: Department of Education and Science.

Ainscow,S. and Muncey,J.(1988).Meeting Individual Needs in The Primary School. London: David Fulton.

Bell,J. (1987). Doing your Research Project. Milton Keynes: Open University Press.

Beveridge,S.(1993).SpecialEducational Needs in Schools. London: Routledge.

Bird,G. and Buckley,S.J. (1994). Meeting The Educational Needs Of Children With Down's Syndrome. A Handbook for Teachers. Portsmouth: University of Portsmouth.

Carpenter,B. (1995). "Tell me about Katie" Attitudes of mainstream 7-8 year olds to a peer with Down syndrome. Down's Syndrome: Research and Practice 3 (2) pp 45-52. Casey,W., Jones,D., Kugler,B and Watkins,B.(1988). Integration of Down syndrome children in the primary school: A longitudinal study of cognitive development and academic attainments. British Journal of Educational Psychology, 58, pp 279-286.

Fulcher,G.(1989). Integrate and mainstream? Comparative issues in the politics of these policies. In Slee, R. (eds) Discipline and Schools. Sydney : Macmillan.

Hegarty,S. (1993). Meeting Special Needs In Ordinary Schools. 2nd edn. London: Cassell Educational Ltd.

Kunzweiler,C. (1982). Mainstreaming will fail unless there is a change in professional attitudes and institutional structure. Education, 102 (3), pp 284-288.
Lorenz,S. (1985). "No visible means of support": A tactical approach to the integration of children with Down syndrome into mainstream nursery provision. Education and Child Psychology, 3 (3) pp 116-122.

Mittler,P. (1992). Preparing all initial teacher training students to teach children with special educational needs: a case study from England. European Journal of Special Needs Education, 7 (1) pp.1-10.

Mortimer,P; Sammons,P; Stoll,L; Lewis,D and Ecob,R (1988). School Matters. London: Open Books.

Petley,K. (1994). An investigation into the experiences of parents and head teachers involved in the integration of primary aged children with Down syndrome into mainstream schools.Down's Syndrome: Research and Practice, 2 (3) pp 91-96.

Sax,G. (1979). Foundations of Educational Research. New Jersey: Prentice Hall.

Sugden,D. (1989). Leeds Education Authority Special Educational Needs Support Programme in Middle and High Schools: Evaluation Report 1. Leeds: University of Leeds

Van Dalen,D.B.(1962)Understanding Educational Research . New York: McGraw-Hill Book Co.

Webster,A and McConnell,C. (1987). Special Needs in Ordinary Schools: Children With Speech and Language Difficulties. London: Cassell Educational Ltd.

Addresses for correspondence:

Heather Petty,

Specialist speech and language teacher, S30 Woodstock Avenue, Grangetown,

Sunderland, SR2 9QD. U.K.

Jane Sadler,

Teacher \& Speech and language therapist, Lecturer in Speech and Education, Department of Speech, University of Newcastle upon Tyne, King George VI Building, Queen Victoria Road, Newcastle upon Tyne, NE1 7RU. U.K. 